\title{
An Examination of Open and Distance Learning Support System using Data Analytics: A Case Study of AIOU
}

\author{
Dr. Muhammad Zafar Iqbal \\ Lecturer \\ Department of Education, AIOU \\ mzafar.iqbal@aiou.edu.pk \\ Kamran Mir \\ Assistant Director \\ Information Technology, AIOU \\ Safia Janjua \\ M. Phil Scholar \\ Department of Education, AIOU
}

\begin{abstract}
This research paper was aimed to explore the trends in Allama Iqbal Open University (AIOU) open and distance learning support system (ODLSS). The study was quantitative in its approach and descriptive research design was adopted. Data were collected through Google data analytics software. In this research the data of ODLSS for four years were included from 2016-2019. To explore the trends in ODLSS the data were collected on number of visitors, visitors by time, city, country, technology, screen resolution, and language used. It was found that over the time period AIOU students increased in accessing the ODLSS using mobiles through android and windows sets. They mostly used chrome to access the website. At present no mobile APP has been developed by AIOU for the mobile users. So, it was recommended that AIOU should develop a mobile application for android users so that students may get information easily anywhere.
\end{abstract}

Keywords: Mobile APP, AIOU, Distance Learning, Trends.

\section{Introduction}

As established by UNESCO (2000), the concept "distance education" reflects a gateway to universal access to training and education, free from place and time restrictions, and offers accessible opportunities of learning for learner classes and individuals. The main elements of distance education have a physical separation between students and teachers through teaching, use of different technologies in order to facilitate communication between the teacher and student and also among the students.

Distance learning centers accommodate students who are full-time workers, people of remote areas who are unable to attend regular classes and military personnel. However, it has 
become an essential part of the educational framework, with continuous growth patterns. Numerous concepts characterize this education trend. Strictly speaking, operation of the student and remote instruction (action of the teacher) together constitute the distance education. Built on Distance Education, over sixty Open Universities run around the globe. Information technology made challenge to distance education far simple and successful. Because of causes of poverty and general inequality of women, the concept of distance education has gained greater importance and recognition within Pakistan. Among Pakistan's poorer classes prevalence of dropouts, shortage of higher education and the levels of literacy is much smaller.

The concept of an "open university" was introduced in the 1972-80. Education Policy with the enunciation of specific values was described in these terms: "Open Universities are being used in several countries to provide education and training to people who cannot leave their homes and jobs for full time studies. An open university will, therefore, be established to provide part-time educational facilities through correspondence courses, tutorials, seminars, workshops, laboratories, television and radio broadcasts and other mass communication media...." (Moore \& Kreasley, 2012).

Allama Iqbal Open University (AIOU) is one of the Giga Universities with more than 1M students per year (Buzkurt, 2019c). It was founded in 1974 and it has an ultimate goal to provide opportunities of education for the poor and for people bound to their homes and occupations. It is also trying to harness new IT to promote schooling in Pakistan. AIOU is offering and increasing the training and educational facilities since its foundation in order to help women and workers improve the skills and their technical abilities. Key characteristics of AIOU can be identified as:

- The country's largest university enrolled more than 1.2 million students currently.

- It is offering almost 2000 courses.

- Pakistan's largest publishing house publishes more than 1.8 million books per annum.

- Greater focus on science and technology through the implementation of services in fields such as Chemistry, Agricultural Extension, Livestock and Food, Forest Extension and Computer Science. 
- It is working with the private sector to set up research centers to provide instruction and realistic guidance in the computer science and management sciences fields.

- Pakistan's biggest teacher education institution with an annual intake of more than 400,000 students.

The links between learners, students, and educational services are becoming less reliant on physical existence rather the latest systems are now getting advanced and easily available; therefore, e-mail, mobile phones and the Web are the new weapons to work for the betterment of distance learning. These new devices and technology have a positive effect which requires time to learn new equipment and use the latest software so that learners can easily access distance learning. As well, teachers will know about the evolution of training demands and the use of future technologies to meet the needs of distance education programs. Rahman's research (2014) centered on the important role of ICT in distance education.

Arshad, Zameer and Bhatti (2017) evaluate research articles in this area to identify emerging trends in distance education and found several new technologies have been used by teachers and students in the area of distance education. Emerging innovations, such as mobile phones, hold great promise as a cognitive communication method for distance education to facilitate immersive social learning whilst overcoming the difficulties of student alienation. It includes the use of smart phones and hand-held IT tools, such as wireless personal assistants. Yousaf's (2007) mobile productivity research has shown that encouraging mobile learning may enhance distance learning by improving contact between distance learners, facilitators, and support staff.

Smart mobile devices are growing in popularity rapidly. These digital devices represent a new wave of technical resources that provide impressive information exposure as well as innovative usage options for parents and educators who look to these apps for future educational benefits. According to Hans and Sidana (2018) mobile is the handy electronic device to approach and share information. When people get Tech Peculiar, almost everyone has a smart phone and the students and their studies even use Android. Notwithstanding mobile device exploration is a well-used tool in the basic and high-level educational system. A variety of Educational apps are available on the smart phone which can teach us almost anywhere. Such 
applications for education continue as a significant benefit to learners as they build a mixture of creativity and primary learning.

In literature and study in this area (Cetron \& Daview, 2003; Dede, Brown \& Whitehouse, 2003; Murali, 2009; Natarajan, 2005; Noreen \&Hafeez, 2013; Ozmen\&Atici, 2014), it is evident that with the rapid changes in the growing world's technological world and distance education, the adoption of new innovations and techniques, new technologies and methods are gradually replacing the old traditions of technology.

\section{Methodology}

The study was quantitative in its approach and descriptive research design was adopted. Data were collected through Google data analytics software. In this research the data of ODLSS for four years were included from 2016-2019. To explore the trends in ODLSS the data were collected on number of visitors, visitors by time, city, country, technology, screen resolution, and language used.

\section{Results}

3.1. AIOU Website Visitors in 2018, 2017, 2016: The number of students of AIOU, who visited the AIOU support system website in the years 2018(1 Jan 2018 to 31 Dec 2018), is given in the figure 1. The data was collected through Google Analytics.

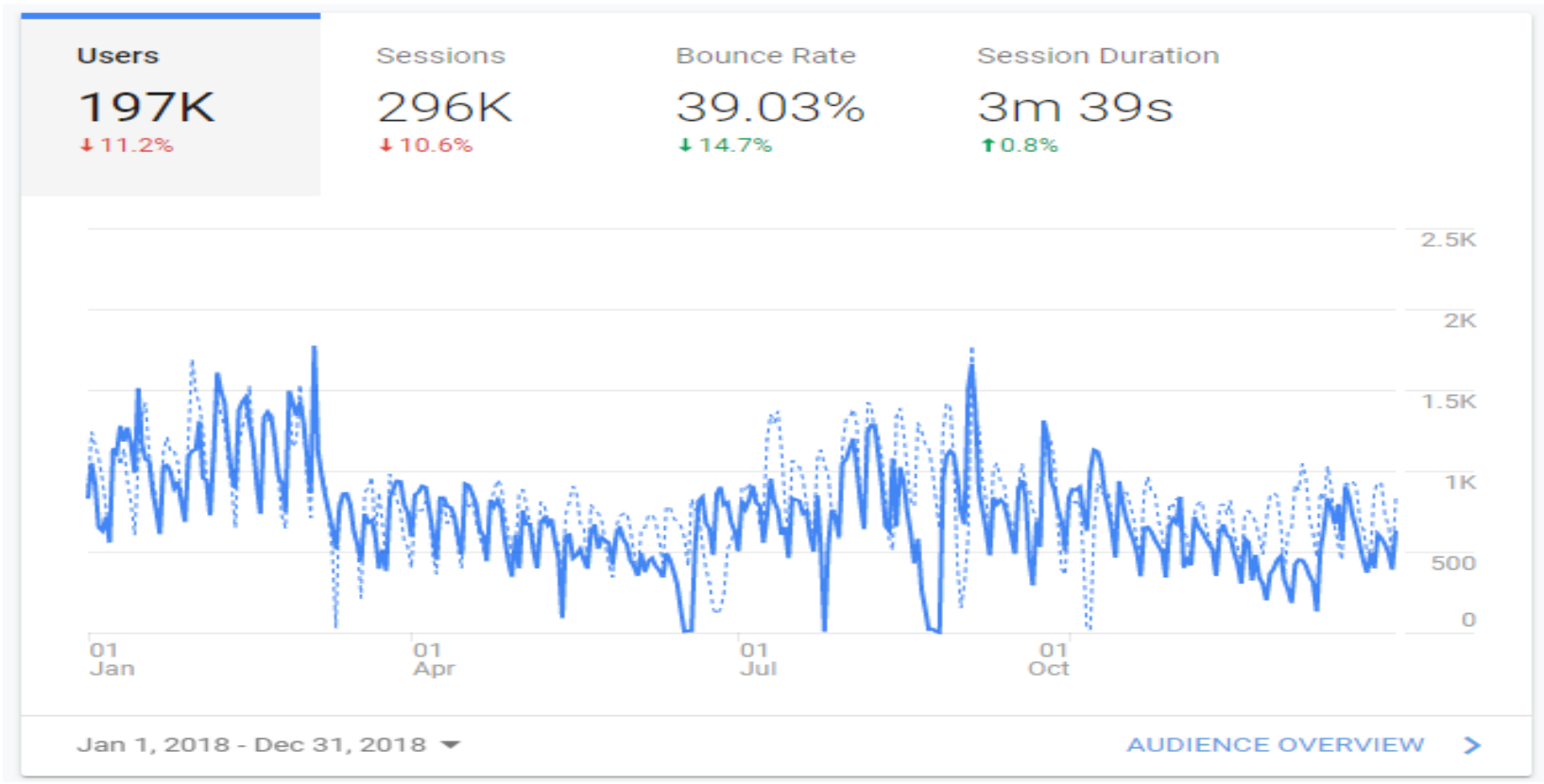

Figure 1: Number of visitors on AIOU support system website in 2018 
Figure 1 shows that around 197,000 users visited AIOU support system website in oneyear duration from 1 January to 31 December 2018. Those 197,000 users created around 296,000 sessions. A session may include multiple page visits by a single user. The average session duration of each user was around 3 minutes and 39 seconds (continually increased as compared with year 2016 and 2017) which is a good sign. The bounce rate percentage was around 39\% (less than previous year) which means that around $39 \%$ (76,830 users) visited only the first landing page of the support system.

The detail of students of AIOU, who visited the AIOU support system website in the years 2017, is given in the figure 2.

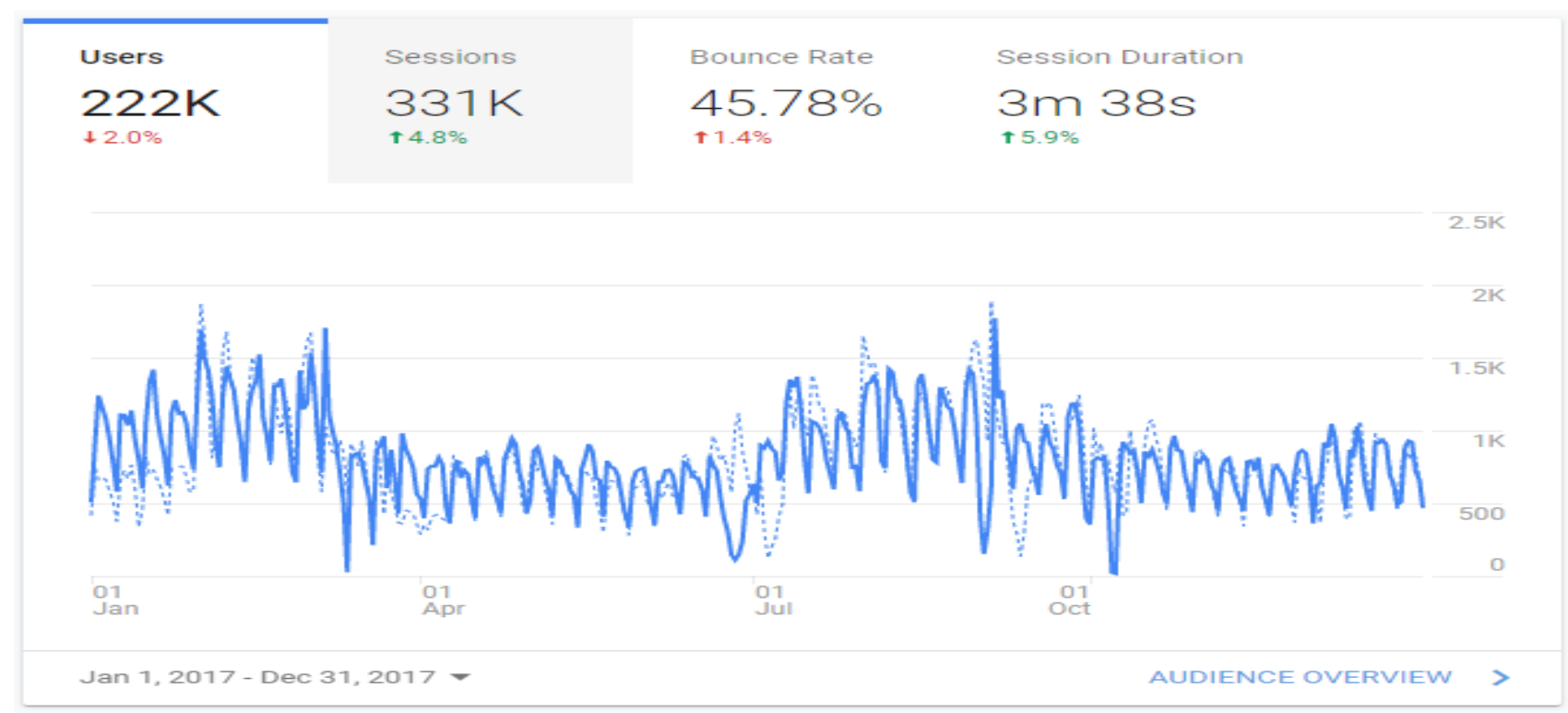

Figure 2: Number of visitors on AIOU support system website in 2017

Figure 2 shows that around 222,000 users visited AIOU support system website in oneyear duration from 01 January to 31 December 2017. Those 222,000 users created around 331,000 sessions. A session may include multiple page visits by a single user. The average session duration of each user was around 3 minutes and 38 seconds which is a good sign. The bounce rate percentage was around 45\% which means that around 45\% (99,900 users) visited only the first landing page of the support system. 
The detail of students of AIOU, who visited the AIOU support system website in the years 2017 , is given in the figure 2 .

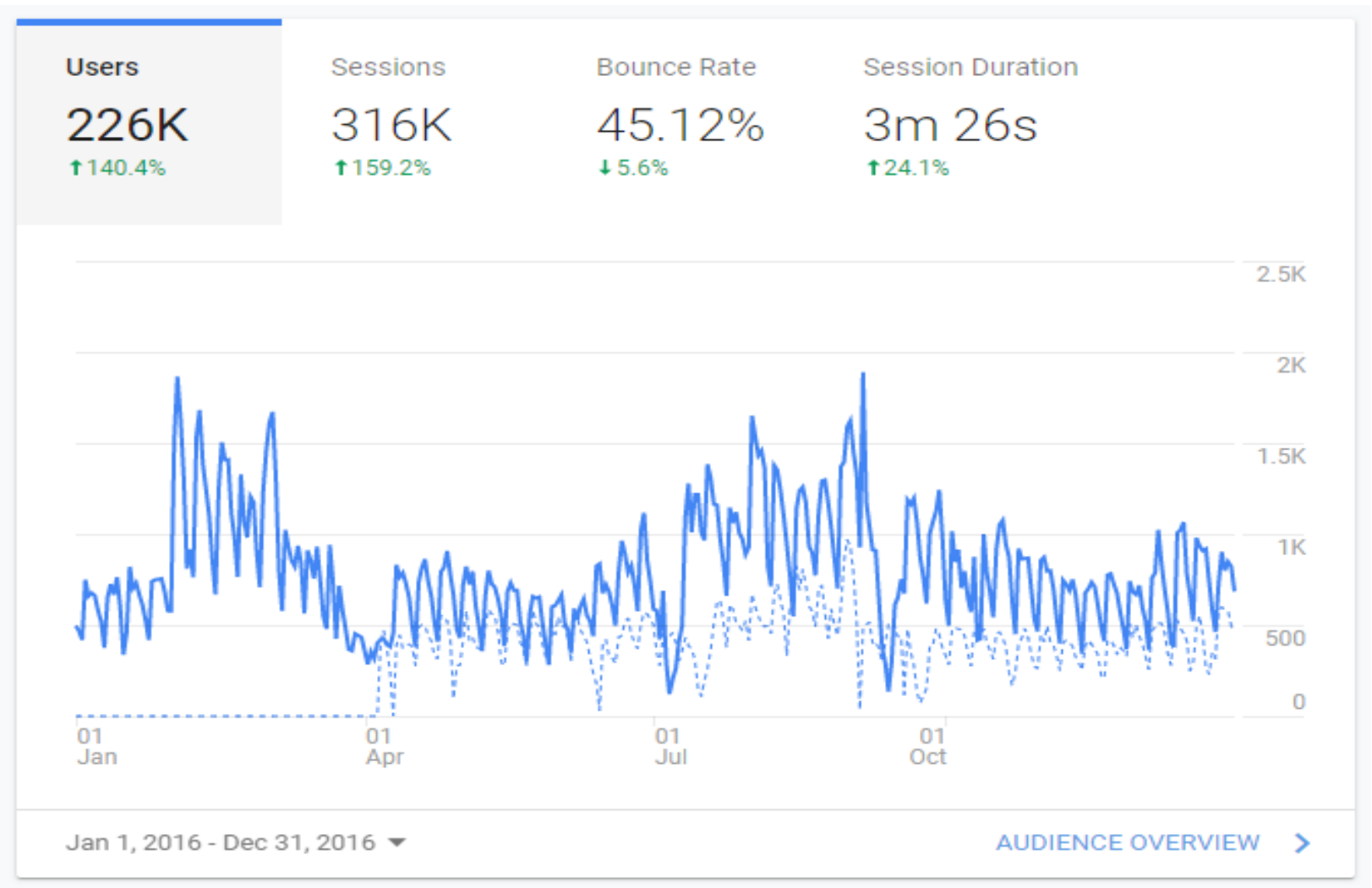

Figure 3: Number of visitors on AIOU support system website in 2017

Figure 3 shows that around 226,000 users visited AIOU support system website in oneyear duration from 1 January to 31 December 2016. Those 226,000 users created around 316,000 sessions. A session may include multiple page visits by a single user. The average session duration of each user was around 3 minutes and 26 seconds which is a good sign. The bounce rate percentage was around 45\% which means that around 45\% (101,700 users) visited only the first landing page of the support system. 


\section{Number of Users by time of the day}

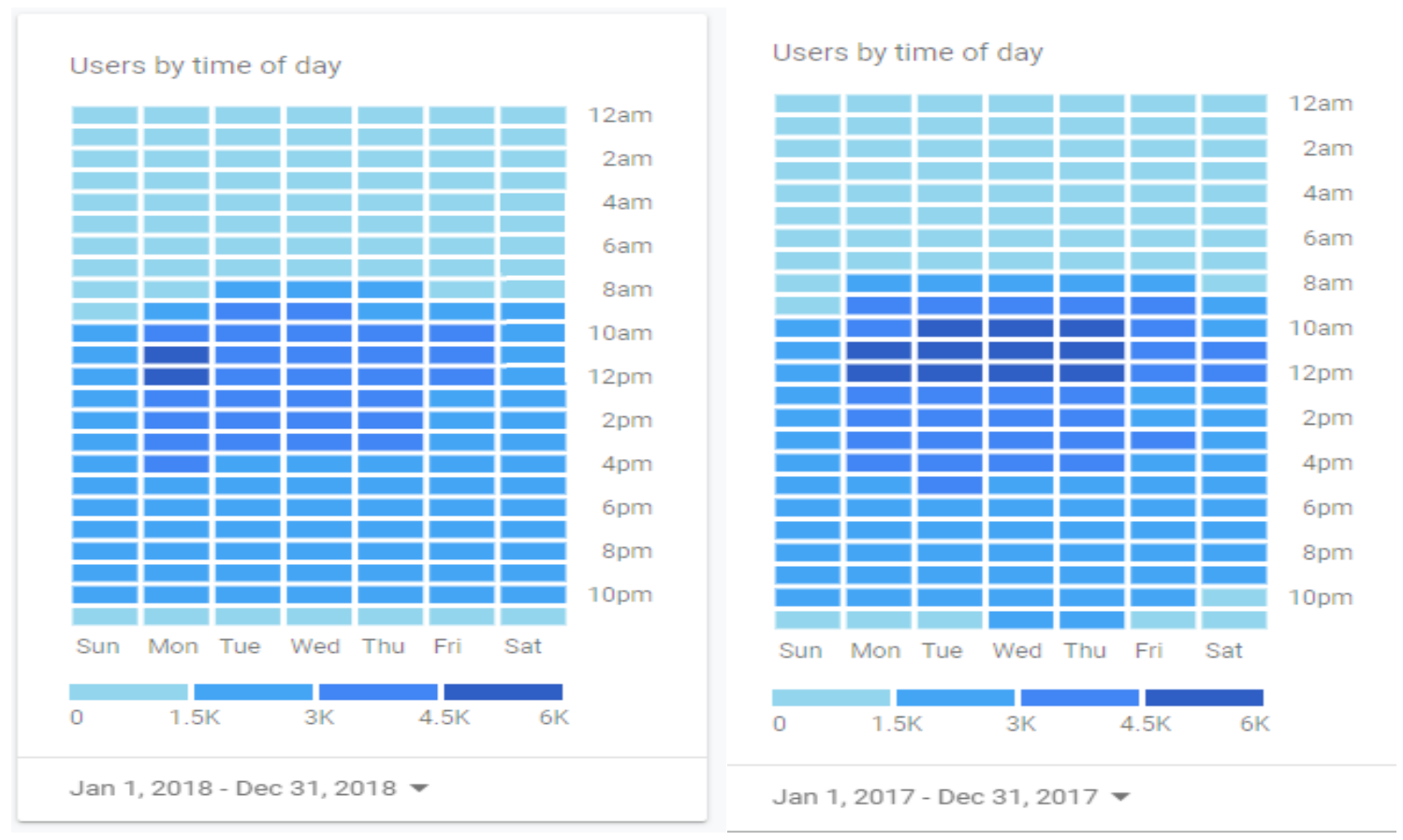

Users by time of day

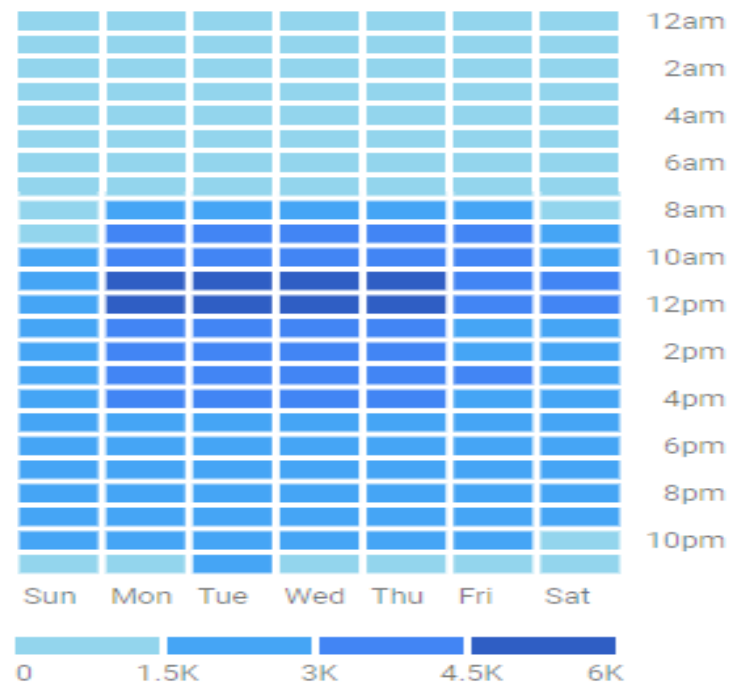

Jan 1, 2016 - Dec 31, 2016 -

Figure 4:Number of visitors by time of day in 2018, 2017, 2016 
Figure 4 shows that in year 2018, the most visited time was $11 \mathrm{am}-12 \mathrm{pm}$ and the day was Monday in which around 6,000 users visited support system website whereas the least visited time slot was 12 am to 8 am and least visited day was Sunday.

In year 2017, the most visited time was 10am-12pm and the days were Monday-Thursday in which around 6,000 users visited support system website whereas the least visited time slot was $12 \mathrm{am}$ to $8 \mathrm{am}$ and least visited day was Sunday.

In year 2016, the most visited time was $11 \mathrm{am}-12 \mathrm{pm}$ and the days were Monday-Thursday in which around 6,000 users visited support system website whereas the least visited time slot was $12 \mathrm{am}$ to $8 \mathrm{am}$ and least visited day was Sunday.

\section{Devices Used}

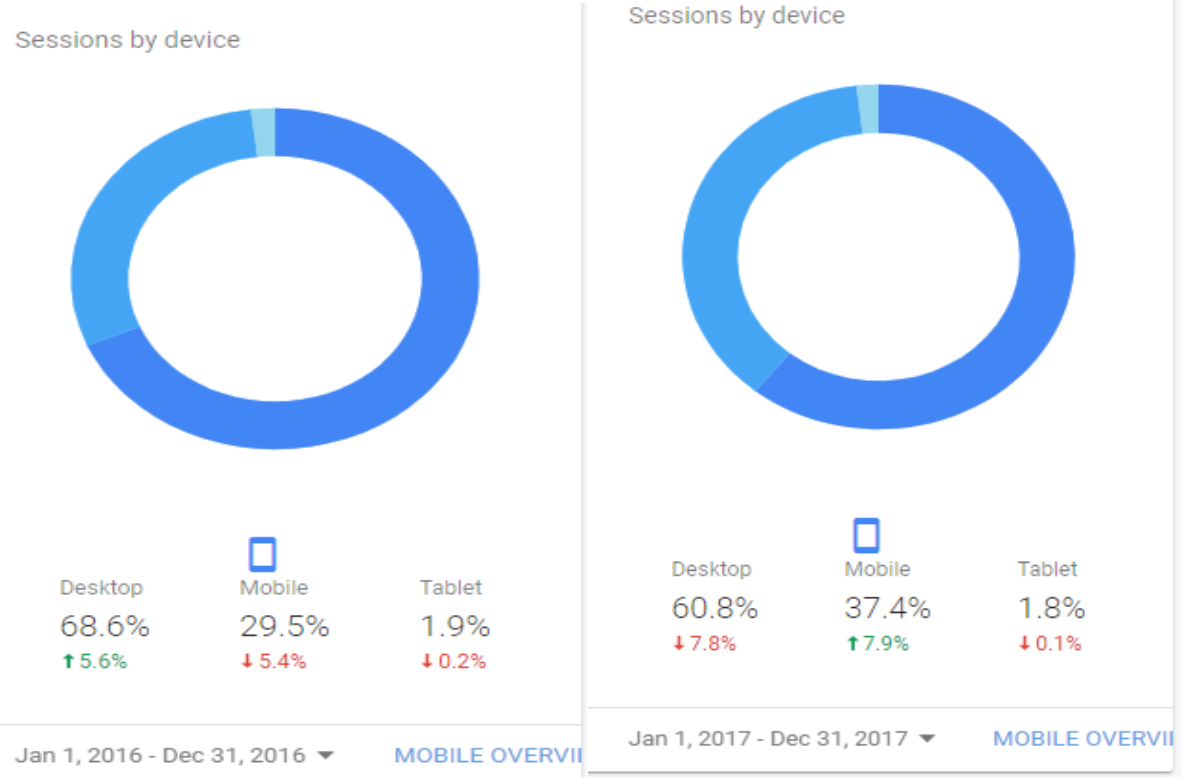



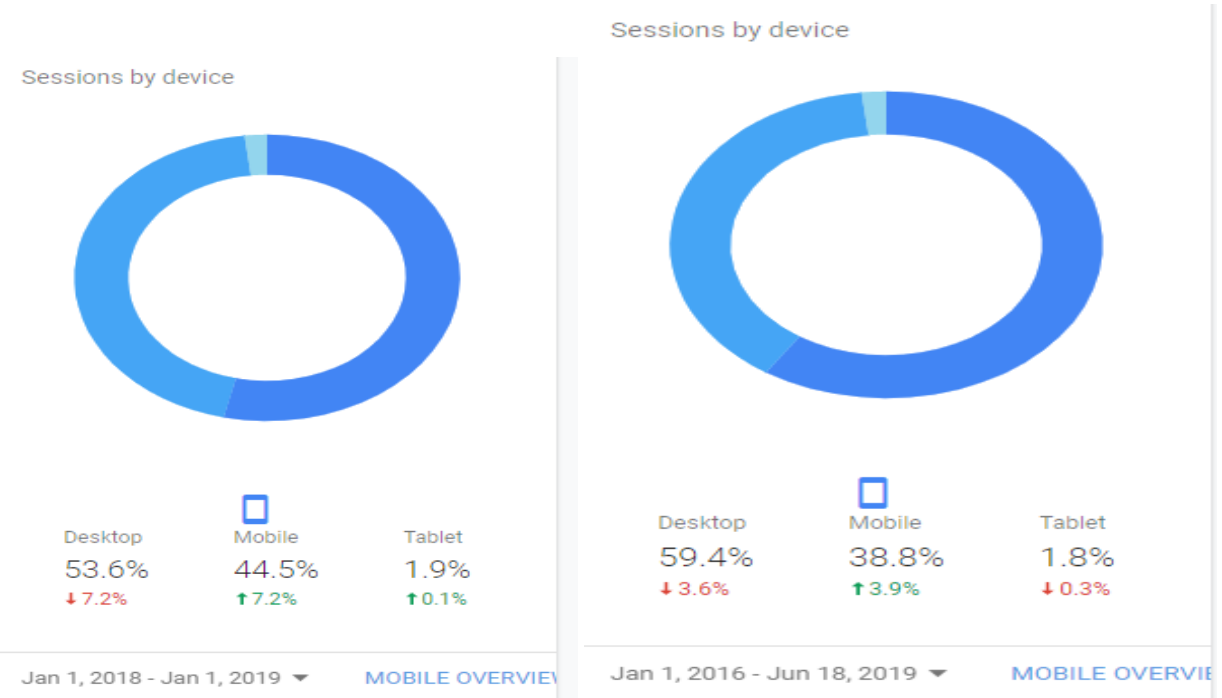

Figure 5: Number of devices used in the years 2019, 2018, 2017, 2016

Figure 5 shows the statistics of sessions by device. It shows that in 2016 the mostly visitors used desktop device (PC) i.e. $68.6 \%$ to access the support system website of AIOU and only 29.5 $\%$ visitors used mobile phone technology. The mobile devices used $37.4 \%$ in 2017 with $7.9 \%$ increased as compared to 2016. This trend increases in 2018 i.e. $44.5 \%$ visitors used mobile phones to accesses the support system website and decrease in the use of desktop (PC) to accesses the website.

\section{Language Selection by Visitors}

Table 1 Detail of Languages selected by visitors of AIOU support system website

\begin{tabular}{lr|l}
\multicolumn{1}{l}{ Language } & Users & $\%$ Users \\
\hline 1. en-us & 581,399 & $80.87 \%$ \\
\hline 2. en-gb & 109,336 & $15.21 \%$ \\
\hline 3. en & $11,773 \mid 1.64 \%$ \\
\hline 4. en-pk & $6,092 \mid 0.85 \%$ \\
\hline 5. (not set) & $4,113 \mid 0.57 \%$ \\
\hline 6. ru & $1,510 \mid 0.21 \%$ \\
\hline 7. en-au & $963 \mid 0.13 \%$ \\
\hline 8. en-ca & $521 \mid 0.07 \%$ \\
\hline 9. ru-ru & $436 \mid 0.06 \%$ \\
\hline 10. ur-pk & $328 \mid 0.05 \%$ \\
\hline
\end{tabular}


The table 1 shows that majority students used English i.e. 80.87\% keyboard as compare to students i.e. $0.05 \%$ who used Urdu keyboard.

\section{Visitors Country Wise}

Table 2. Detail of visitors from different countries

\begin{tabular}{|c|c|c|}
\hline Country & Users & $\%$ Users \\
\hline 1. (a Pakistan & 669,278 & $92.54 \%$ \\
\hline 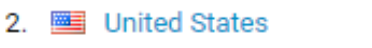 & 10,949 & $1.51 \%$ \\
\hline 3. United Arab Emirates & 9,346 & $1.29 \%$ \\
\hline 4. 回 Saudi Arabia & 5,521 & $0.76 \%$ \\
\hline 5. 2 India & 4,252 & $0.59 \%$ \\
\hline 6. (not set) & 3,677 & $0.51 \%$ \\
\hline 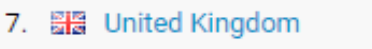 & 2,621 & $0.36 \%$ \\
\hline 8. 国 Kenya & 2,241 & $0.31 \%$ \\
\hline 9. $\Xi$ Netherlands & 2,100 & $0.29 \%$ \\
\hline 10. $=$ Sudan & 1,898 & $0.26 \%$ \\
\hline
\end{tabular}

Majority students belong to Pakistan who visits AIOU support system, however, the user accessing from other countries needs to be investigated and monitored as well for possible potential students or hackers as well.

\section{Visitors City wise from Pakistan}

Table 3. Detail of visitors from different cities of Pakistan

\begin{tabular}{lc|c}
\multicolumn{1}{c}{ City } & Users $\%$ Users \\
\hline 1. Lahore & 210,727 & $28.26 \%$ \\
\hline 2. Islamabad & 126,879 & $17.02 \%$ \\
\hline 3. Rawalpindi & 65,404 & $8.77 \%$ \\
\hline 4. Karachi & 64,354 & $8.63 \%$ \\
\hline 5. (not set) & 50,770 & $6.81 \%$ \\
\hline 6. Faisalabad & 45,591 & $6.11 \%$ \\
\hline 7. Peshawar & 26,499 & $3.55 \%$ \\
\hline 8. Multan & 25,644 & $3.44 \%$ \\
\hline 9. Gujranwala & 19,121 & $2.56 \%$ \\
\hline 10. Bahawalpur & 13,040 & $1.75 \%$ \\
\hline
\end{tabular}


Table 3 shows that majority students belongs to Lahore city i.e. $28.26 \%$ which is highly correlated with number of actual enrollment from Lahore City and total population of Lahore followed by Islamabad and Rawalpindi i.e. $17.02 \%$ and $8.77 \%$ respectively.

\begin{tabular}{l|c|c}
\multicolumn{1}{c}{ Browser } & Users $\%$ Users \\
\hline 1. Chrome & 512,548 & $71.45 \%$ \\
\hline 2. Firefox & 50,889 & $7.09 \%$ \\
\hline 3. UC Browser & 44,606 & $6.22 \%$ \\
\hline 4. Android Webview & 24,681 & $3.44 \%$ \\
\hline 5. Opera Mini & 15,010 & $2.09 \%$ \\
\hline 6. Safari & 14,665 & $2.04 \%$ \\
\hline 7. Opera & 14,300 & $1.99 \%$ \\
\hline 8. Android Browser & $12,650 \mid 1.76 \%$ \\
\hline 9. Internet Explorer & $11,430 \mid 1.59 \%$ \\
\hline 10. Samsung Internet & 7,526 & $1.05 \%$
\end{tabular}

Majority (71\%) users use Google Chrome as an Internet Browser followed by Firefox and UC browser. These statistics are very helpful for IT/Developer team to make sure all future and existing applications must be supported by these browsers at least.

\begin{tabular}{lc|c}
\multicolumn{1}{l}{ Operating System } & Users $\%$ Users \\
\hline 1. Windows & 421,520 & $58.53 \%$ \\
\hline 2. Android & 257,178 & $35.71 \%$ \\
\hline 3. (not set) & 15,895 & $2.21 \%$ \\
\hline 4. ios & $15,394 \mid 2.14 \%$ \\
\hline 5. Linux & $2,825 \mid 0.39 \%$ \\
\hline 6. Windows Phone & $2,775 \mid 0.39 \%$ \\
\hline 7. Macintosh & $2,276 \mid 0.32 \%$ \\
\hline 8. Nokia & 1,128 & $0.16 \%$ \\
\hline 9. Symbianos & 545 & $0.08 \%$
\end{tabular}


Most of the students use Microsoft Windows as an Operating System, whereas there is a huge population using Android O/S as compared with iOS so there is dire need of mobile application for students and especially for android users.

\begin{tabular}{ll|l}
\multicolumn{1}{c}{ Service Provider } & Users & $\%$ Users \\
\hline 1. pakistan telecommuication company limited & 204,469 & $26.67 \%$ \\
\hline 2. for karachi igw & 69,897 & $4.29 \%$ \\
\hline 3. telenor pakistan & 32,920 & $4.29 \%$ \\
\hline 4. usf dslam central & 31,054 & $4.05 \%$ \\
\hline 5. telenor pakistan (pvt) Itd & 24,676 & $3.22 \%$ \\
\hline 6. mobilink a subsidiary of the orascom & 23,071 & $3.01 \%$ \\
\hline 7. plot no $181-186$ street no. 2 i-9/2 industrial area & 18,396 & $2.40 \%$ \\
\hline 8. nayatel (pvt) Itd & 18,270 & $2.38 \%$ \\
\hline 9. usf dslam south & 17,949 & $2.34 \%$ \\
\hline 10. mobilink mobile internet & 14,658 & $1.91 \%$
\end{tabular}

As HEIs and ODL institutes are moving towards online learning, the above statistics will give good idea for technology implementers which implementing technology based solutions.

Mobile

$\mathbf{O} / \mathbf{S}$

\begin{tabular}{lr|l}
\multicolumn{1}{l}{ Operating System } & Users $\%$ Users \\
\hline 1. Android & 257,178 & $89.99 \%$ \\
\hline 2. ios & 15,394 & $5.39 \%$ \\
\hline 3. (not set) & $6,875 \mid 2.41 \%$ \\
\hline 4. Windows Phone & $2,775 \mid 0.97 \%$ \\
\hline 5. Windows & $1,447 \mid 0.51 \%$ \\
\hline 6. Nokia & $1,128 \mid 0.39 \%$ \\
\hline 7. Symbianos & $545 \mid 0.19 \%$ \\
\hline 8. BlackBerry & 354 & $0.12 \%$ \\
\hline 9. Samsung & 74 & $0.03 \%$ \\
\hline 10. Sony & 4 & $0.00 \%$ \\
\hline
\end{tabular}


Around 90\% students use Android in mobile which means as a first priority, android application is required to be developed for students to provide effective support.

\section{Mobile Screen}

\begin{tabular}{ll|l}
\multicolumn{1}{c}{ Screen Resolution } & Users $\%$ Users \\
\hline 1. $360 \times 640$ & 120,814 & $42.50 \%$ \\
\hline 2. $320 \times 534$ & 16,789 & $5.91 \%$ \\
\hline 3. $320 \times 570$ & 16,552 & $5.82 \%$ \\
\hline 4. $720 \times 1280$ & 13,656 & $4.80 \%$ \\
\hline 5. $412 \times 732$ & 9,094 & $3.20 \%$ \\
\hline 6. $480 \times 800$ & 8,825 & $3.10 \%$ \\
\hline 7. $360 \times 720$ & 7,985 & $2.81 \%$ \\
\hline 8. $540 \times 960$ & 4,697 & $1.65 \%$ \\
\hline 9. $480 \times 854$ & 4,321 & $1.52 \%$
\end{tabular}

Screen resolution statistics can help the UI/UX designers to design the existing or future application as per above requirements.

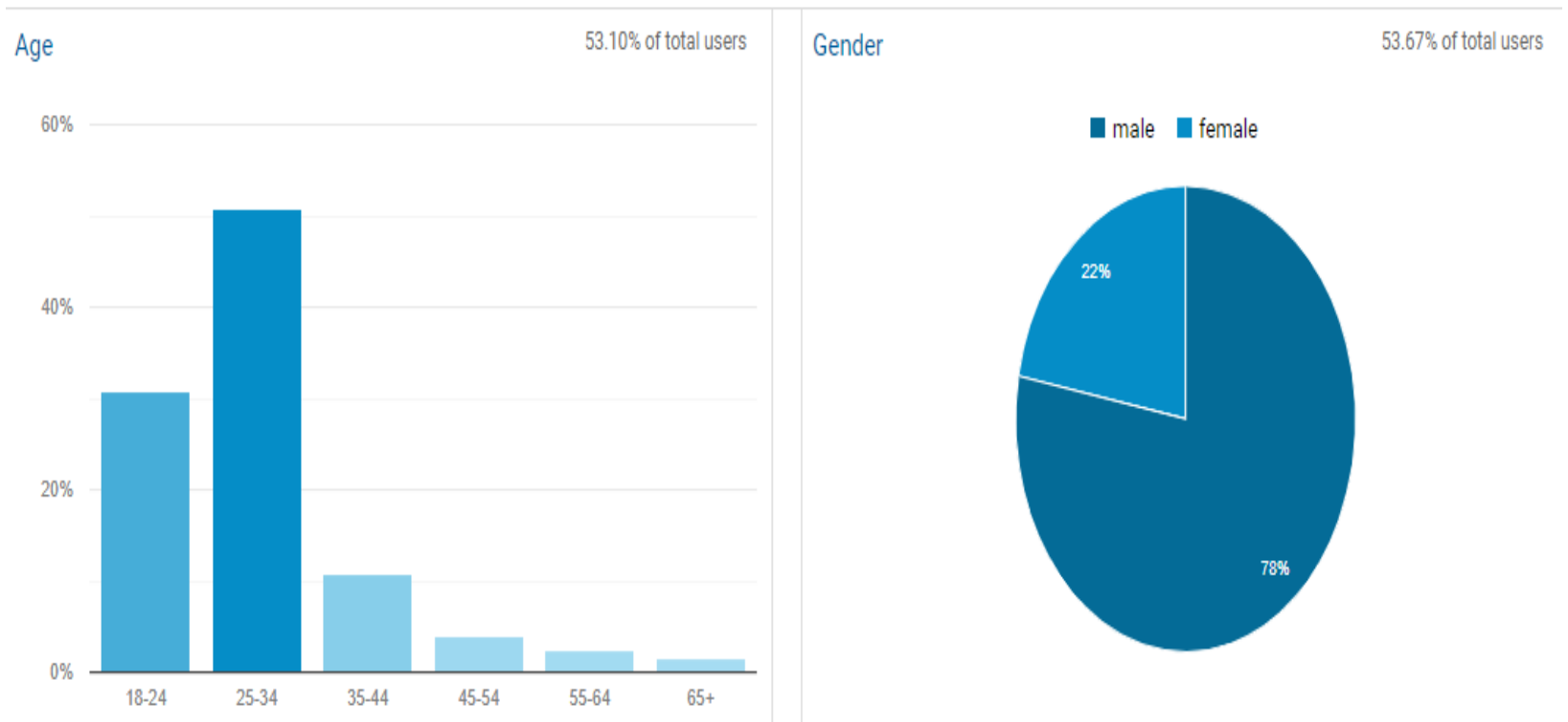

Figure 6: Percentage of visitors demographics by age and gender 
The above figure shows that majority of visitors with age 25-34. Moreover, $78 \%$ students who visited AIOU were males.

\section{Top Channels}

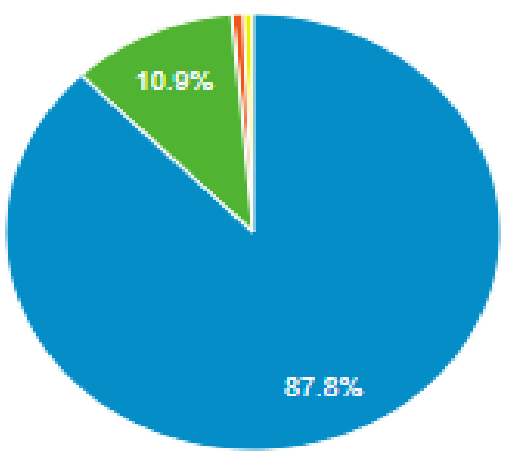

Direct

Organic Search

Social

Referral

(Other)

Figure 7: Percentage of visitors from different channels

Figure 7 shows that the students visiting the support system are majority from AIOU main website or directly visiting the URL. However, there is very less percentage from organic search (Google search) or social media which means the proper dissemination of support system needs to be spread via social media platforms (WhatsApp, Facebook, Linkedin etc.)

\begin{tabular}{|c|c|c|c|c|c|c|}
\hline & \multicolumn{3}{|l|}{ Acquisition } & \multicolumn{3}{|l|}{ Behavior } \\
\hline & Users & New Users & Sessions & Bounce Rate & $\begin{array}{l}\text { Pages/ } \\
\text { Session }\end{array}$ & $\begin{array}{l}\text { Avg. Session } \\
\text { Duration }\end{array}$ \\
\hline & 720,596 & 719,572 & $1,082,014$ & $42.56 \%$ & 4.02 & 00:03:36 \\
\hline 1 Direct & 639,289 & & & $42.56 \%$ & & \\
\hline 2 Organic Search & 79,160 & & & $41.16 \%$ & & \\
\hline $3 \square$ Social & 5,185 & & & $49.60 \%$ & & \\
\hline $4 \square$ Referral & 4,742 & & & $55.33 \%$ & & \\
\hline $5 \square$ (Other) & 2 & & & $100.00 \%$ & & \\
\hline
\end{tabular}

Figure 8: Percentage of visitors' behavior (Bounce rate) 
In the figure 8 trend shows the user behavior, the users visiting directly through website has high bounce rate as compared with students visiting through organic search. This means the students visiting through organic search are more genuinely concerned about the resolution of their problem.

\section{Conclusions}

The study put forward the following conclusions:

1. It was concluded that AIOU need to upgrade their ICT system with the present needs and demands of the students.

2. Students visiting directly through website has high bounce rate as compared with students visiting through organic search.

3. More than 80 percent of the students used English language for their search. Out of the world, Pakistan has most of the students to search about the AIOU out of which majority of students from Lahore used the site for their search.

4. There was increased in accessing the support system website of AIOU through Mobile phone from 2016 to 2019 as compared to Desktop.

\section{Recommendations}

One the basis of findings following were the recommendations:

- At present no APP for Android mobiles has been developed by AIOU for the mobile users, So, it was recommended that AIOU should develop a mobile application for android users so that students may get information easily anywhere.

- Mobile APP should be in English language for the convenience of students all around the world.

\section{References}

Arshad, M., Zamir, S., and Bhatti, R. (2017). Emerging technological trends in distance education. Pakistan Journal of Distance and Online Learning, 3(2), 71-84.

Bozkurt, A. (2019c). The historical development and adaptation of open universities in Turkish context: Case of Anadolu University as a Giga university. International Review of Research in Open and Distributed Learning, 20(4), 36-59. doi: http://doi.org/10.19173/irrodl.v20i4.4086 
Cetron, M. J. \&Daview, O. (2003). 50 trends shaping the future. Special Report Published by the World Future Society.

Dede, C., Brown, T. \& Whitehouse, P. (2003). Designing and studying learning experiences that use multiple interactive media to bridge distance and time. In: Vrasidas, C. \& Glass, G. V. (editors). Distance education and distributed learning. London: Eurospan.

Hans, G., \&Sidana, P.H. (2018). Mobile learning application and its usage among students in education. Journal of Emerging Technologies and Innovative Research (JETIR), 5(1), 984998.

Moore, M. G., Krearsly, G. (2012). Distance education: A systems view of online learning. Wadsworth, Cangage Learning.

Murali, M. (2009). Web-enabled User Support Services System in Distance Education.

Natarajan, M. (2005). Innovative teaching techniques for distance education. Communications of the International Information Management Association, 5 (4), 73 - 79.

Noreen, Z. \& Hafeez, A. (2013). A study on adopting emerging methodological trends by distance learners. Paper presented at 3rd International Conference on Business Management Feb 2013 at University of Management and Technology, Lahore.

Ozmen, B. \&Atici, B. (2014). Learners' views regarding the use of social networking sites in distance learning. The International Review of Research in Open and Distributed Learning (IRRODL), 15(4).

Rahman, H. (2014). The role of ICT in open and distance education. Turkish Online Journal of Distance Education (TOJDE), 15(4), 162. 